\title{
Proximal Trauma Increases Risk of Venous Thrombosis in Soft Tissue Reconstruction of Open Lower Limb Fractures
}

\author{
Nilay G. Yalcin, Frank Bruscino-Raiola and Scott Ferris* \\ Plastic, Hand and Faciomaxillary Surgery Unit, Alfred Health, Melbourne, VIC, Australia
}

Lower limb salvage after major trauma is a complex undertaking. For patients who have suffered multi-level trauma to their lower limb we postulated that pelvic injury or ipsilateral lower limb injury proximal to the site of a free flap may increase the rate of post-operative complications. All patients who underwent lower limb free flap reconstruction as a result of acute trauma between January 2010 and December 2017 were included. The patients were divided into the study group (50 patients), who sustained a lower limb or pelvic injury proximal to the free flap site, and control group (91 patients) who did not sustain proximal lower limb or pelvic trauma. Complication rates were compared between the

OPEN ACCESS

Edited by:

Jan A. Plock,

University of Zurich, Switzerland

Reviewed by:

Erkki Juhani Tukiainen,

University of Helsinki, Finland

Rik Osinga,

University Hospital of

Basel, Switzerland

*Correspondence:

Scott Ferris

scott@scottferris.com.au

Specialty section:

This article was submitted to Reconstructive and Plastic Surgery,

a section of the journal

Frontiers in Surgery

Received: 19 June 2020 Accepted: 14 December 2020

Published: 15 January 2021

Citation:

Yalcin NG, Bruscino-Raiola F and

Ferris S (2021) Proximal Trauma

Increases Risk of Venous Thrombosis in Soft Tissue Reconstruction of Open Lower Limb Fractures.

Front. Surg. 7:574498.

doi: 10.3389/fsurg.2020.574498 two groups. Overall, the proximal trauma group anastomotic thrombosis rate of $18.0 \%$ was significantly higher than the control group thrombosis rate of $2.2 \%$. There was no statically significant difference in rates of hematoma, swelling or infection. Flap loss rate in the proximal trauma group was $4.0 \%$, compared to the control group at $2.2 \%$. All patients with a failed flap went onto have a successful reconstruction with a subsequent flap in the acute admission and there were no amputations. In the proximal injury study group despite the significantly increased rate of microvascular thrombosis requiring revision, the ultimate primary free flap survival rate was still 96\%. Overall, severe coexisting proximal trauma predicted a higher venous microvascular complication rate but was not a contraindication to limb salvage.

Keywords: limb salvage, microsurgery, trauma, complication, thrombosis

\section{INTRODUCTION}

Traumatic lower limb defects require a multidisciplinary approach for the salvage of the limb. The decision to reconstruct the limb is to allow the patient to ultimately restore physical, social and economic well-being (1-4). The primary aim of flap reconstruction is to achieve adequate soft tissue coverage of underlying structures to promote bony healing, preserve tendinous function, protect from infection and act as a vehicle for the transport of antimicrobial agents to the site of infection, thereby optimizing healing and function. For severe lower limb trauma, the basic principles include aggressive, often multiple debridements (5-8), skeletal stabilization and early soft tissue coverage (9-11). Where there is significant or extensive trauma to local tissue, particularly in the distal third of the leg or foot, the best alternative for wound coverage is usually a free flap (12-14). Fasciocutaneous, myocutaneous or muscle-only free flaps are often utilized, however the choice of tissue transfer may also include vascularized bone in order to bridge a segmental bone loss $(15,16)$. 
If the patient is not deemed suitable for reconstruction or reconstruction fails, the alternative treatment is amputation. The success rate of free flaps depends on a number of factors. Age, infection, delayed coverage and presence of co-morbidities have been associated with a higher risk of flap failure in previous studies (17-20). It is generally agreed that early reconstruction is associated with a lower incidence of infection. However, the definition of "early" varies between different studies, extending between 1 and 15 days (5-7, 9, 20-27).

It is usual in major trauma for patients to sustain injuries at multiple sites. Few studies however, have evaluated the success rate of flap surgery in the setting of associated injuries. A previous study by Rinker et al. focusing on a pediatric population did not establish any link between mechanism or type of injury with complication rate in 26 patients in total (28).

The aim for this study was to evaluate the outcomes of adult lower limb free flaps in traumatic lower limb wounds when there was a concomitant pelvic or ipsilateral lower limb injury proximal to the site of the free flap, which we hypothesized could affect free flap complication rates and patient outcomes.

\section{MATERIALS AND METHODS}

All patients undergoing lower limb free flap reconstruction as a result of acute leg and/or foot open fractures and/or dislocations between January 2010 to December 2017 were included in this study. The patients were identified and data collected from our lower limb trauma database and medical records. Data collected included patient co-morbidities, smoking status, age, type of flap, type of arterial and venous anastomoses and complications.

All eligible patients were divided into two groups- one with no injury of the lower limb/pelvis proximal to the free flap site (control group) and the second group with concomitant significant injury to the lower limb/pelvis proximal to the flap site (proximal trauma group). The nature of proximal injuries included, but was not limited to pelvic, femoral or knee fractures or dislocations. One patient from the proximal trauma group sustained a degloving injury over a femoral fracture but otherwise the remaining proximal injuries were all closed fractures or dislocations. There was no recorded direct vascular injury in any patient within the study group. The outcomes between the two groups were compared to determine if proximal injury was associated with increased complication rates.

A comparison between the two groups were made using univariate statistical analysis. $P$-value $<0.05$ was considered statistically significant. The project received ethics approval from the Alfred Health ethics committee prior to commencement.

\section{RESULTS}

We analyzed all 141 patients who underwent lower limb flap reconstruction as a result of trauma at the Alfred between 2010 and 2017 inclusive. Overall, 50 patients were identified as being in the proximal trauma group and 91 patients in the control group with no proximal trauma (Table 1 ).
TABLE 1 | Baseline demographics for proximal trauma group and control group.

\begin{tabular}{llll}
\hline Baseline demographics & $\begin{array}{l}\text { Proximal trauma } \\
\boldsymbol{n}=\mathbf{5 0}\end{array}$ & $\begin{array}{l}\text { Control } \\
\boldsymbol{n}=\mathbf{9 1}\end{array}$ & $\boldsymbol{p}$-value \\
\hline Age & & & \\
Mean (Range) & $44.2(16-80)$ & $45.8(21-82)$ & - \\
Smoker & $12(24.0 \%)$ & $12(13.2 \%)$ & 0.10 \\
Diabetes & $4(8.0 \%)$ & $8(8.8 \%)$ & 1.0 \\
PVD & $1(2.0 \%)$ & $3(3.3 \%)$ & 1.0 \\
Flap & & & \\
Muscle & $13(26.0 \%)$ & $18(19.8 \%)$ & 0.39 \\
Fasciocutaneous & $37(74.0 \%)$ & $73(80.2 \%)$ & \\
\hline
\end{tabular}

TABLE 2 | Pre-operative arterial patency of lower limb.

\begin{tabular}{lcc}
\hline $\begin{array}{l}\text { Angiogram/CTA } \\
\text { findings }\end{array}$ & $\begin{array}{c}\text { Proximal trauma } \\
\text { (47 of 50 patients } \\
\text { scanned) }\end{array}$ & $\begin{array}{c}\text { Control (83 of 91 } \\
\text { patients scanned) }\end{array}$ \\
\hline $\begin{array}{l}\text { Three vessel run } \\
\text { off }\end{array}$ & 35 & 71 \\
Two vessel run off & 9 & 11 \\
One vessel run off & 3 & 1 \\
\hline
\end{tabular}

Fasciocutaneous flaps were more frequently used in both our proximal trauma and control groups compared to muscle or myocutaneous flaps (Table 1). Fasciocutaneous flaps were utilized in $74.0 \%$ proximal trauma and $80.2 \%$ control group patients with muscle/myocutaneous flaps used in $26.0 \%$ of proximal trauma and $19.8 \%$ of control group patients.

All trauma patients were routinely started on prophylactic dose of Enoxaparin daily on admission except one patient. This patient had suffered intra-cranial and liver hemorrhages therefore was not started on prophylactic anticoagulation until deemed safe. After the free flap reconstruction, all patients either remained on prophylactic enoxaparin or were changed to prophylactic Heparin 5,000 units BD or TDS depending on surgeon preference.

Three patients in the control and five patients in the trauma groups were changed to therapeutic anticoagulation (heparin infusion or therapeutic enoxaparin) prior to their free flap due to DVT and/or PE diagnosed during their work-up. Therapeutic anticoagulation was continued for these patients post-operatively.

Angiogram or CTA was obtained for 130 of the 141 patients included in this study. The 11 patients who did not have preoperative arteriography were patients who had injuries at the level of the ankle/foot with clinically perfused feet. The results of the arteriography are in Table 2. Phlebography was not routinely obtained.

Majority of our flaps underwent end-to-end arterial anastomosis to either posterior tibial (PTA) or anterior tibial (ATA) vessels (134 of 141 flaps). There were four flaps with end-to-side arterial anastomoses and three flaps that were 
TABLE 3 | Choice of recipient artery for free flap.

\begin{tabular}{lcc}
\hline Recipient artery & Proximal trauma $(\boldsymbol{n}=\mathbf{5 0})$ & Control $(\boldsymbol{n}=\mathbf{9 1})$ \\
\hline Posterior Tibial Artery (PTA) & $22(44.0 \%)$ & $48(52.7 \%)$ \\
Anterior Tibial Artery (ATA) & $27(54.0 \%)$ & $37(40.7 \%)$ \\
Dorsalis Pedis (DP) & $0(0.0 \%)$ & $3(3.3 \%)$ \\
Descending Genicular & $1(2.0 \%)$ & $1(1.1 \%)$ \\
Artery (DGA) & $0(0.0 \%)$ & $1(1.1 \%)$ \\
Superficial Femoral Artery & & \\
(SFA) & $0(0.0 \%)$ & $1(1.1 \%)$ \\
Popliteal Artery (PA) & & \\
\hline
\end{tabular}

TABLE 4 | Choice of recipient vein/s for free flap.

\begin{tabular}{lcc}
\hline $\begin{array}{l}\text { Recipient venous anatomosis } \\
\text { system }\end{array}$ & Proximal trauma $(\boldsymbol{n}=\mathbf{5 0})$ & Control $(\boldsymbol{n}=\mathbf{9 1})$ \\
\hline $\begin{array}{l}\text { Vena comitans - single } \\
\text { anastomosis }\end{array}$ & $9(18.0 \%)$ & $15(16.5 \%)$ \\
$\begin{array}{l}\text { Vena comitans - two or three } \\
\text { anastomoses }\end{array}$ & $26(52.0 \%)$ & $50(54.9 \%)$ \\
$\begin{array}{l}\text { Vena comitans (one or two } \\
\text { anastomoses) + Superficial vein } \\
\text { (one anastomosis) }\end{array}$ & $15(30.0 \%)$ & $23(25.3 \%)$ \\
$\begin{array}{l}\text { Superficial vein only (single } \\
\text { anastomosis) }\end{array}$ & $0(0.0 \%)$ & $3(3.3 \%)$ \\
\end{tabular}

TABLE 5 | Free flap donor site preference.

\begin{tabular}{lcc}
\hline Donor site preference & Proximal trauma $(\boldsymbol{n}=\mathbf{5 0})$ & Control $(\boldsymbol{n}=\mathbf{9 1})$ \\
\hline Distant & $16(32.0 \%)$ & $29(31.9 \%)$ \\
Contralateral lower limb & $30(60.0 \%)$ & $57(62.6 \%)$ \\
Ipsilateral lower limb & $4(8.0 \%)$ & $5(5.5 \%)$ \\
\hline
\end{tabular}

anastomosed as arterial flow through flaps. Choice of recipient arteries are outlined in Table 3.

Couplers were introduced to our unit during the course of the study. Couplers were used in 41 of the control group (45.1\%) and 26 patients of the trauma group (52.0\%). There was no statistically significant correlation between the introduction of couplers and the rate of venous anastomosis related complications. The veins used in microsurgery were based on surgeon preference and availability. Generally, patients had venous anastomoses to at least one vena comitans of the utilized donor artery, with or without using either a second vena comitans or a cutaneous vein. A summary of the venous recipients is shown on Table 4.

In majority of our patients, the donor choice was the contralateral leg or a distant site (upper limb or trunk) over the ipsilateral thigh (Table 5).

Complication rates for each group are outlined in Table 6. The most common reason for unplanned return to theater in the proximal trauma group was to explore the anastomosis which occurred in $18.0 \%$. All of these patients had venous outflow compromise which was managed by revising the venous
TABLE 6 | Complication rates between proximal trauma group and control group.

\begin{tabular}{lccc}
\hline Complications & $\begin{array}{c}\text { Proximal } \\
\text { trauma } \\
(\boldsymbol{n}=\mathbf{5 0})\end{array}$ & $\begin{array}{c}\text { Control } \\
(\boldsymbol{n}=\mathbf{9 1})\end{array}$ & $\boldsymbol{p}$-value \\
\hline Return to theater (all causes) & $14(28.0 \%)$ & $19(20.8 \%)$ & 0.34 \\
Exploration of anastomosis & $9(18.0 \%)$ & $4(4.4 \%)$ & $0.013^{\star}$ \\
Confirmed thrombosis rate & $9(18.0 \%)$ & $2(2.2 \%)$ & $0.002^{\star}$ \\
Partial necrosis & $6(12.0 \%)$ & $4(4.4 \%)$ & 0.17 \\
Hematoma/swelling only & $3(6.0 \%)$ & $6(6.6 \%)$ & 1.00 \\
Infection (requiring return to theater) & $0(0.0 \%)$ & $2(2.2 \%)$ & 0.54 \\
Complete flap loss & $2(4.0 \%)$ & $2(2.2 \%)$ & 0.62 \\
\hline
\end{tabular}

*Statistically significant.

anastomosis either directly or utilizing vein grafts. In the control group, the return to theater rate for exploration of anastomoses was $4.4 \%$. Venous thrombosis requiring revision was present in only half of these re-explored control cases. Overall, therefore, the study group anastomotic thrombosis rate was $18.0 \%$ but the control group thrombosis rate was $2.2 \%$. Both groups had similar rates of return to theater for hematoma (proximal trauma $6.0 \%$ vs. control 6.6\%). Total unplanned return to theater rate for all causes in the proximal trauma patients was higher at $28.0 \%$ compared to the control group $20.8 \%$ but this did not reach statistical significance. The overall flap loss rate in the proximal trauma group was ultimately $4.0 \%$, compared to the control group at $2.2 \%(p=0.62)$. All patients with a failed flap went onto have a successful reconstruction with a subsequent flap in the acute admission and there were no amputations. There were no cases of arterial insufficiency causing a return to theater in either the study or the control groups.

\section{DISCUSSION}

Overall, there was no statistically significant difference in the rate of post-operative haematoma, swelling or infection between the proximal trauma and control groups (Table 6). To salvage the lower limb in significant trauma the initial, and most important, step is to prevent infection by early, aggressive debridement and appropriate antibiotics. This initial phase requires communication between senior plastic and orthopedic surgeons. Only two patients in the total study needed to return to theater for infection during their acute admission. Both of these patients were in the control group.

The most important finding in this study was the statically higher rate of microvascular anastomosis thrombosis in the study group (18.0\%) compared to the control group (2.2\%). This equates to a just over eight times higher rate of microvascular thrombosis in the proximal trauma group compared to the control. All of these patients had a venous thrombosis compromising flap perfusion. Where possible, the area of thrombosis was resected and the venous anastomosis was revised directly. In the cases where this was either not possible or deemed too high risk, a reversed vein graft was used to anastomose the flap vein to appropriately located and patent recipient vein. After 
any anastomotic revision, patients were started on therapeutic heparin post-operatively, unless there was a contraindication.

The higher incidence of venous thrombosis in the proximal trauma group may be related to the nature of the trauma the limb suffered. Having a multi-level injury implies that the limb has undergone a more substantial direct force with shear and crush forces applied across a larger area compared to the control group patients. In this type of injury, veins are particularly vulnerable to endothelial damage, which may not always be evident at the time of the free flap reconstruction. When these veins with endothelial injury are used in the micro-anastomosis of the free flap, their physiology may be further stressed, gradually leading to venous thrombosis. Another possibility is that those patients with proximal trauma may have had a greater incidence of occult deep venous thromboses, which contributed to increased stasis within the draining venous system and increased the risk of anastomotic thrombosis.

We had two complete free flap losses in each group. All four flap losses were following venous thrombosis. One of these four patients, also developed an infection within the flap. All four patients went onto having a successful subsequent reconstruction-one with a loco-regional flap, three with a second free flap. There were no amputations in the acute admission.

We did have minor partial necrosis in six patients from the proximal trauma group (12\%) and four patients from the control group (4.4\%). For the six patients in the proximal trauma group, four had minor area of flap necrosis following venous congestion and one following evacuation of a haematoma. All five of these patients underwent a minor debridement and SSG to the area of necrosis. The sixth patient from the proximal trauma group underwent debridement and loco-regional flap coverage for tip necrosis of a free flap. For the control group, on the other hand, two of the four partial necrosis cases occurred following venous congestion. The other two were flap tip necrosis. All four patients in the control group had minor partial flap necrosis which were debrided and covered with SSG.

Our unit aims to complete skeletal and soft tissue reconstruction within 1 week of injury. This, however, is not possible in those patients who have suffered other injuries that need to be addressed prior to free flap reconstruction. Godina et al. have recommended flap coverage within 3 days of injury as being associated with less infection and less flap failure (9). Subsequent studies have looked at different timeframes for early coverage. Fischer et al. defined early coverage as within 10 days alongside of another subgroup who received coverage between 11 days and 6 weeks and a third subgroup that received coverage after 6 weeks (22). The early coverage group had lower incidence of infection and shorter hospital stay. The BAPRAS/BOA guidelines on "Standard of Management of Open Fractures of the Lower Limb" recommend coverage within 7 days prior to vessels becoming friable or fibrosed (29). Numerous studies support early coverage, although the definition of early may vary from within $24 \mathrm{~h}$ to 15 days (23-27).

There is evidence to support the use both of fasciocutaneous and myocutaneous/muscle flap compositions and often the decision is based upon surgeon preference. Muscle flaps may provide an advantage in obliterating dead-space to prevent haematoma or seroma. There have been early studies to suggest muscle flaps may provide a higher resistance to infection and provide better vascularity which has resulted in their recommendation by some authors $(30,31)$. Small and Mollan (23) have reviewed 168 open tibial fractures over 15 years and have favored muscle coverage based on experimental evidence in animal models (32-35) and their own complication rates which were reported as highest in the fasciocutaneous flaps. More recent research has however refuted this premise (36-38). Paro et al. have published a retrospective study comparing their outcomes for muscle vs. fasciocutaneous free flaps (36). In a total of 86 free muscle flaps and 35 free fasciocutaneous flaps over 10 years, there was no statistically significant difference in major or minor acute complications. Muscle and fasciocutaneous flaps were comparable in outcomes in a multi-center retrospective review of 518 patients by Cho et al. (37). Cherubino et al. (38) also found no convincing evidence to support muscle or fasciocutaneous flaps in lower limb trauma in their large-scale systematic review of lower limb trauma reconstruction.

\section{CONCLUSION}

This study shows a significantly greater microvascular thrombosis rate in patients with pelvic or ipsilateral limb trauma proximal to the site of a lower extremity free flap. Despite this eight-fold increase in venous thrombosis rate, the ultimate overall primary flap survival rate in this more injured study group was still $96 \%$. We have changed our practice in light of this study, and recommend:

1. Ultrasound studies looking for limb deep vein thrombosis prior to free flap reconstruction in proximally injured patients.

2. Consideration for increased anticoagulation therapy where safe in proximally injured patients.

3. Selection whenever possible of clinically easily monitored free flaps which are either fasciocutaneous or myocutaneous for early detection of thromboses, should they occur.

We believe with appropriate judgement and case selection, that severe coexisting proximal trauma predicts a higher venous microvascular complication rate but is not a contraindication to limb salvage.

\section{DATA AVAILABILITY STATEMENT}

The raw data supporting the conclusions of this article will be made available by the authors, without undue reservation.

\section{ETHICS STATEMENT}

The studies involving human participants were reviewed and approved by The Alfred Ethics Committee. Written informed consent for participation was not required for this study in accordance with the national legislation and the institutional requirements. 


\section{AUTHOR CONTRIBUTIONS}

SF and FB-R conceived this study. NY collected and analyzed the data for this study. All authors contributed to the preparation of this manuscript and approved its final submission.

\section{REFERENCES}

1. Giessler GA, Schmidt AB. Muscular and osteomuscular peroneus brevis flaps. Oper Orthop Traumatol. (2013) 25:131-44. doi: 10.1007/s00064-012-0202-7

2. Hierner EL, Corterier C, Hierner R. Lateral supramalleolar flaps for reconstruction in the ankle and foot. Oper Orthop Traumatol. (2013) 25:12230. doi: 10.1007/s00064-012-0199-y

3. Kneser U, Beier JP, Dragu A, Arkudas A, Horch RE. Peroneal artery perforator flap. Oper Orthop Traumatol. (2013) 25:1705. doi: 10.1007/s00064-012-0200-9

4. Knobloch K, Herold C, Vogt PM. Free latissimus dorsi flap transfer for reconstruction of soft tissue defects of the lower extremity. Oper Orthop Traumatol. (2012) 24:122-30. doi: 10.1007/s00064-011-0094-y

5. Byrd HS, Cierny G 3rd, Tebbetts JB. The management of open tibial fractures with associated soft-tissue loss: external pin fixation with early flap coverage. Plast Reconstr Surg. (1981) 68:73-82. doi: 10.1097/00006534-198107000-00016

6. Byrd HS, Spicer TE, Cierney G 3rd. Management of open tibial fractures. Plast Reconstr Surg. (1985) 76:719-30. doi: 10.1097/00006534-19851100000011

7. Cierny G 3rd, Byrd HS, Jones RE. Primary versus delayed soft tissue coverage for severe open tibial fractures. A comparison of results. Clin Orthop Relat Res. (1983) 178:54-63. doi: 10.1097/00003086-19830900000008

8. Yaremchuk MJ, Brumback RJ, Manson PN, Burgess AR, Poka A, Weiland AJ. Acute and definitive management of traumatic osteocutaneous defects of the lower extremity. Plast Reconstr Surg. (1987) 80:1-14. doi: 10.1097/00006534-198707000-00002

9. Godina M. Early microsurgical reconstruction of complex trauma of the extremities. Plast Reconstr Surg. (1986) 78:28592. doi: 10.1097/00006534-198609000-00001

10. Parrett BM, Matros E, Pribaz JJ, Orgill DP. Lower extremity trauma: trends in the management of soft-tissue reconstruction of open tibiafibula fractures. Plast Reconstr Surg. (2006) 117:1315-22. discussion: 234. doi: 10.1097/01.prs.0000204959.18136.36

11. Reddy V, Stevenson TR. MOC-PS(SM) CME article: lower extremity reconstruction. Plast Reconstr Surg. (2008) 121 (Suppl. 4):1-7. doi: 10.1097/01.prs.0000305928.98611.87

12. Chan JK, Harry L, Williams G, Nanchahal J. Soft-tissue reconstruction of open fractures of the lower limb: muscle versus fasciocutaneous flaps. Plast Reconstr Surg. (2012) 130:284e-95e. doi: 10.1097/PRS.0b013e3182 $589 \mathrm{e} 63$

13. Harry LE, Sandison A, Pearse MF, Paleolog EM, Nanchahal J. Comparison of the vascularity of fasciocutaneous tissue and muscle for coverage of open tibial fractures. Plast Reconstr Surg. (2009) 124:1211-9. doi: 10.1097/PRS.0b013e3181b5a308

14. Franken JM, Hupkens P, Spauwen PH. The treatment of soft-tissue defects of the lower leg after a traumatic open tibial fracture. Eur J Plast Surg. (2010) 33:129-33. doi: 10.1007/s00238-010-0405-9

15. Beris AE, Lykissas MG, Korompilias AV, Vekris MD, Mitsionis GI, Malizos $\mathrm{KN}$, et al. Vascularized fibula transfer for lower limb reconstruction. Microsurgery. (2011) 31:205-11. doi: 10.1002/micr.20841

16. Han CS, Wood MB, Bishop AT, Cooney WP 3rd. Vascularized bone transfer. J Bone Joint Surg Am. (1992) 74:14419. doi: 10.2106/00004623-199274100-00002

17. Baumeister SP, Spierer R, Erdmann D, Sweis R, Levin LS, Germann GK. A realistic complication analysis of 70 sural artery flaps in a multimorbid patient group. Plast Reconstr Surg. (2003) 112:129-40. discussion: 412. doi: 10.1097/01.PRS.0000066167.68966.66

\section{ACKNOWLEDGMENTS}

Authors would like to acknowledge Paul Eldho for his contribution to the statistical analysis of the study data.

18. Maffi TR, Knoetgen J 3rd, Turner NS, Moran SL. Enhanced survival using the distally based sural artery interpolation flap. Ann Plast Surg. (2005) 54:302-5. doi: 10.1097/01.sap.0000146682.75075.b2

19. Vaienti L, Di Matteo A, Gazzola R, Pierannunzii L, Palitta G, Marchesi A. First results with the immediate reconstructive strategy for internal hardware exposure in non-united fractures of the distal third of the leg: case series and literature review. J Orthop Surg Res. (2012) 7:30. doi: 10.1186/1749-799X-7-30

20. Liu DS, Sofiadellis F, Ashton M, MacGill K, Webb A. Early soft tissue coverage and negative pressure wound therapy optimises patient outcomes in lower limb trauma. Injury. (2012) 43:772-8. doi: 10.1016/j.injury.2011.09.003

21. Lo $\mathrm{CH}$, Leung $\mathrm{M}$, Baillieu $\mathrm{C}$, Chong EW, Cleland $\mathrm{H}$. Trauma centre experience: flap reconstruction of traumatic lower limb injuries. ANZ J Surg. (2007) 77:690-4. doi: 10.1111/j.1445-2197.2007.04188.x

22. Fischer MD, Gustilo RB, Varecka TF. The timing of flap coverage, bonegrafting, and intramedullary nailing in patients who have a fracture of the tibial shaft with extensive soft-tissue injury. J Bone Joint Surg Am. (1991) 73:1316-22. doi: 10.2106/00004623-199173090-00005

23. Small JO, Mollan RA. Management of the soft tissues in open tibial fractures. Br J Plast Surg. (1992) 45:571-7. doi: 10.1016/0007-1226(92) 90022-P

24. Francel TJ, Vander Kolk CA, Hoopes JE, Manson PN, Yaremchuk MJ. Microvascular soft-tissue transplantation for reconstruction of acute open tibial fractures: timing of coverage and long-term functional results. Plast Reconstr Surg. (1992) 89:478-87. discussion: 88-9. doi: 10.1097/00006534-199203000-00014

25. Ninkovic M, Schoeller T, Benedetto KP, Anderl H. Emergency free flap cover in complex injuries of the lower extremities. Scand J Plast Reconstr Surg Hand Surg. (1996) 30:37-47. doi: 10.3109/02844319609072403

26. Sinclair JS, McNally MA, Small JO, Yeates HA. Primary free-flap cover of open tibial fractures. Injury. (1997) 28:581-7. doi: 10.1016/S0020-1383(97) 00093-4

27. Hertel R, Lambert SM, Muller S, Ballmer FT, Ganz R. On the timing of softtissue reconstruction for open fractures of the lower leg. Arch Orthop Trauma Surg. (1999) 119:7-12. doi: 10.1007/s004020050346

28. Rinker B, Valerio IL, Stewart DH, Pu LL, Vasconez HC. Microvascular free flap reconstruction in pediatric lower extremity trauma: a 10-year review. Plast Reconstr Surg. (2005) 115:161824. doi: 10.1097/01.PRS.0000160698.68234.6C

29. Surgeons BAoPRaA. BAPRAS and BOA Standards for the Management of Open Fractures of the Lower Limb. London: Royal Society of Medicine Press Ltd. (2009).

30. Chang N, Mathes SJ. Comparison of the effect of bacterial inoculation in musculocutaneous and random-pattern flaps. Plast Reconstr Surg. (1982) 70:1-10. doi: 10.1097/00006534-198207000-00002

31. Tropet Y, Garbuio P, Obert L, Ridoux PE. Emergency management of type IIIB open tibial fractures. Br J Plast Surg. (1999) 52:46270. doi: 10.1054/bjps.1999.3166

32. Gothman L. Local arterial changes associated with diastasis in experimental fractures of the rabbit's tibia treated with intramedullary nailing. A microangiographic study. Acta Chir Scand. (1962) 123:104-10.

33. Trueta J, Buhr AJ. The vascular contribution to osteogenesis. V. The vasculature supplying the epiphysial cartilage in rachitic rats. J Bone Joint Surg Br. (1963) 45:572-81. doi: 10.1302/0301-620X.45B3.572

34. Rhinelander FW. The normal microcirculation of diaphyseal cortex and its response to fracture. J Bone Joint Surg Am. (1968) 50:784800. doi: 10.2106/00004623-196850040-00016

35. Holden CE. The role of blood supply to soft tissue in the healing of diaphyseal fractures. An experimental study. J Bone Joint Surg Am. (1972) 54:9931000. doi: 10.2106/00004623-197254050-00005 
36. Paro J, Chiou G, Sen SK. Comparing muscle and fasciocutaneous free flaps in lower extremity reconstruction-does it matter? Ann Plast Surg. (2016) 76 (Suppl. 3):S213-5. doi: 10.1097/SAP.0000000000000779

37. Cho EH, Shammas RL, Carney MJ, Weissler JM, Bauder AR, Glener AD, et al. Muscle versus fasciocutaneous free flaps in lower extremity traumatic reconstruction: a multicenter outcomes analysis. Plast Reconstr Surg. (2018) 141:191-9. doi: 10.1097/PRS.0000000000003927

38. Cherubino M, Corno M, D'Arpa S, Di Summa P, Pellegatta I, Valdatta L, et al. Muscle versus fasciocutaneous flap in lower limb reconstruction: is there a best option? J Reconstr Microsurg. (2017) 33:S27-33. doi: 10.1055/s-0037-1606559
Conflict of Interest: The authors declare that the research was conducted in the absence of any commercial or financial relationships that could be construed as a potential conflict of interest.

Copyright (c) 2021 Yalcin, Bruscino-Raiola and Ferris. This is an open-access article distributed under the terms of the Creative Commons Attribution License (CC BY). The use, distribution or reproduction in other forums is permitted, provided the original author(s) and the copyright owner(s) are credited and that the original publication in this journal is cited, in accordance with accepted academic practice. No use, distribution or reproduction is permitted which does not comply with these terms. 